\title{
DÜBLIN
}

Technological University Dublin

ARROW@TU Dublin

2009-01-01

\section{Optical Patterning of Photopolymerisable Materials}

\author{
Kevin Trainer \\ Drexel University \\ Kevin Wearen \\ Technological University Dublin \\ Dimana Nazarova \\ Bulgarian Academy of Sciences
}

See next page for additional authors

Follow this and additional works at: https://arrow.tudublin.ie/cieocon2

Part of the Optics Commons

\section{Recommended Citation}

Trainer, K., Wearen, K.J. \& Nazarova, D. (2009). Optical patterning of photopolymerisable materials. Conference proceedings of the International commission for Optics Topical meeting on Emerging trends and novel materials in photonics, vol. 1288, pg.184-187. doi:10.1063/1.3521355

This Conference Paper is brought to you for free and open access by the Centre for Industrial and Engineering Optics at ARROW@TU Dublin. It has been accepted for inclusion in Conference Papers by an authorized administrator of ARROW@TU Dublin. For more information, please contact arrow.admin@tudublin.ie, aisling.coyne@tudublin.ie, gerard.connolly@tudublin.ie.

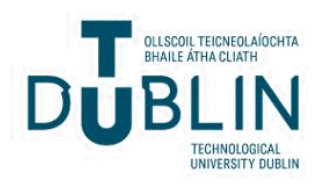




\section{Authors}

Kevin Trainer, Kevin Wearen, Dimana Nazarova, Izabela Naydenova, and Vincent Toal 
Dublin Institute of Technology

ARROW@DIT

Articles

Centre for Industrial and Engineering Optics

2009-01-01

\section{Optical patterning of photopolymerisable materials}

Kevin Trainer

Drexel University

Kevin Wearen

Dublin Institute of Technology

Dimana Nazarova

Bulgarian Academy of Sciences

Izabela Naydenova

Dublin Institute of Technology, izabela.naydenova@dit.ie

Vincent Toal

Dublin Institute of Technology, vincent.toal@dit.ie

\section{Recommended Citation}

T. Trainer, K. Wearen, D. Nazarova, I. Naydenova, V. Toal, Optical patterning of photopolymerisable materials, Conference proceedings of the International commission for Optics Topical meeting on Emerging trends and novel materials in photonics, v.1288, 184-187, 2009. 


\title{
Optical patterning of photopolymerisable materials
}

\author{
K. Trainer ${ }^{\mathrm{b}}$, K. Wearen ${ }^{\mathrm{a}}$, D. Nazarova ${ }^{\mathrm{c}}$, I. Naydenova ${ }^{\mathrm{a}, \mathrm{c} *}, \mathrm{~V}$. Toal $^{\mathrm{a}}$ \\ ${ }^{a}$ Centre for Industrial and Engineering Optics, School of Physics, Dublin Institute of Technology, Dublin \\ 8 , Ireland \\ ${ }^{b}$ Department of Physics, Drexel University, Philadelphia, USA; visiting UREKA student , FOCAS Institute, \\ Dublin 8, Ireland \\ ${ }^{c}$ Central Laboratory of Optical Storage and Processing of Information, Bulgarian Academy of Sciences, \\ Bl. 101, Acad. G. Bonchev Str., 1113 Sofia, Bulgaria \\ *izabela.naydenova@dit.ie
}

\begin{abstract}
Holographic recording is an effective approach for photopolymer surface patterning. It has been previously utilised in acrylamide-based photopolymers and a spatial frequency limit of $200 \mathrm{l} / \mathrm{mm}$ has been observed. We report the successful inscription of submicrometer resolution patterns. The spatial frequency response has been extended to 1550 $1 / \mathrm{mm}$ by introduction of thermal post recording treatment. Initial results from the optical patterning utilising a spatial light modulation (SLM) reveal that the amplitude of the photoinduced surface relief structures is larger in comparison to the amplitude obtained by holographic recording.
\end{abstract}

Keywords: photopolymers, photoinduced surface relief, optical patterning, acrylamide based photopolymer PACS: 42.40.-I, 42.70.Ln, 81.65.Cf, 68.35.bm

\section{INTRODUCTION}

Self-processing acrylamide-based photopolymers for volume holography have been successfully developed at the Centre for Industrial and Engineering Optics for more than a decade [1-4]. It has been observed that during holographic recording in these materials in addition to the volume holograms, surface relief modulation is inscribed [5-7]. Optically recorded surface relief modulation has been previously observed and characterised in other photopolymer systems [8-11]. A common feature of the surface relief structures in self-processing photopolymers is their limited range of spatial frequency. It has been observed that the amplitude of the surface relief profile decreases with the increase of the spatial frequency and the upper resolution limit in these materials doesn't exceed $5001 / \mathrm{mm}$.

For many practical applications such as fabrication of switchable electro-optical devices and design of optical sensors sub-micron resolution is required. Such resolution is achievable by photolithography or electron beam lithography, but both techniques are expensive and the first requires wet post processing of the material while the second one has a small throughput.

In the present paper two different approaches to the optical patterning of the surface of a photopolymerisable material - holographic recording and illumination through a spatial light modulator (SLM) have been adopted. 3D surface relief structures have been inscribed and studied using white light surface profilometry and atomic force microscopy. Sub micrometer size structures have been inscribed by introduction of post exposure thermal treatment of the holographically recorded photopolymer layers. In addition, surface relief structures inscribed by illumination through a SLM are compared to these obtained by holographic recording.

\section{EXPERIMENTAL}

\section{Materials}

The investigated acrylamide-based photopolymer layer consists of a polyvinyl alcohol binder, two monomersacrylamide and N,N'-methylenebisacrylamide, triethanolamine as an initiator and Erythrosine B photosensitive dye. Once mixed, $0.3 \mathrm{ml}$ of the solution was spread on a $75 \mathrm{~mm}$ x $25 \mathrm{~mm}$ glass substrate. The films were ready for use after drying for 5 hours. The typical layer thickness was $25 \pm 2 \mu \mathrm{m}$. 


\section{Recording set -up}

The photoinduced surface relief was inscribed by recording transmission holographic gratings ranging from 200 - 1550 lines $/ \mathrm{mm}$. A Verdi ${ }^{\mathrm{TM}}$ laser $(532 \mathrm{~nm})$ was used for holographic recording. The optical set-up is shown in figure 1. The spatial frequency of recording was controlled by moving the sample along a rail as well as adjusting the mirror (see Fig. 1). The recording intensity was $10 \mathrm{~mW} / \mathrm{cm}^{2}$. Exposure time was varied from 50 to 100 seconds.

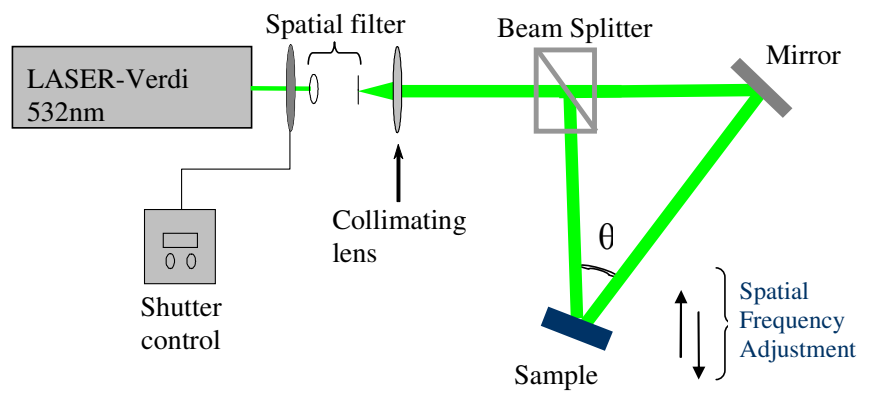

FIGURE 1. Optical set up for holographic patterning.

\section{Experimental procedure}

The experimental procedure is shown in fig.2. After exposure to light the layers were bleached and exposed to high temperature. The temperature was varied from 160 to $210^{\circ} \mathrm{C}$ with a rate of $1^{\circ} \mathrm{C} / \mathrm{min}$. The photopolymer surface was studied using a white light interferometric (WLI) surface profiler MicroXAM S/N 8038 and an atomic force microscope AFM Easy Scan model 2. These two methods both reveal the surface profile of the structure, with each providing attractive qualities. The WLI delivers fast and reliable information with resolution limit of $10001 / \mathrm{mm}$, whereas the AFM delivers a much higher resolution picture, albeit requiring more time.

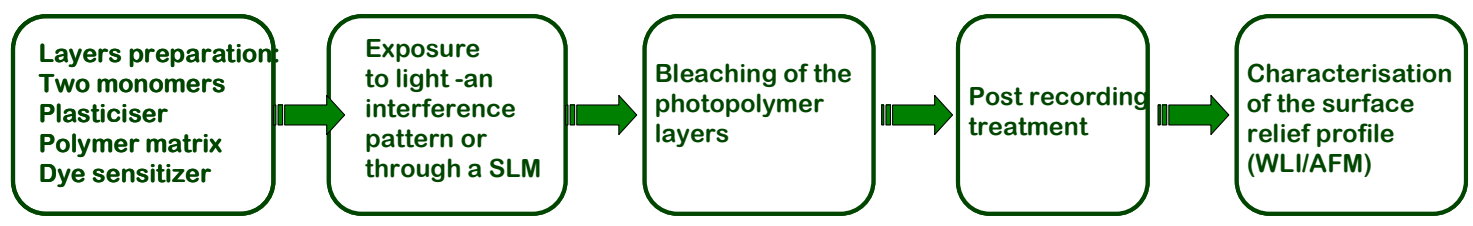

FIGURE 2. Experimental procedure

RESULTS AND DISCUSSION

\section{Holographic patterning}

AFM scans of the photopolymer layers were carried out immediately after holographic exposure. No periodical surface relief was formed when the interference pattern was of frequency above $500 \mathrm{l} / \mathrm{mm}$. When the exposed area was probed with one of the recording beams it was observed that a volume phase holographic grating had been recorded. After baking at high temperature this latent pattern was developed and a periodical surface relief profile was observed in the AFM pictures (Figure 3). A set of samples recorded at the same conditions was transferred to the oven which was initially set at $120^{\circ} \mathrm{C}$. The temperature was set to rise by $1^{\circ} \mathrm{C} / \mathrm{min}$. Two samples were removed from the oven every $10 \mathrm{~min}$ and their surface was examined by AFM. The amplitude of the surface relief profile 
(SRA) increased with the increase of baking temperature whose maximum of $210^{\circ} \mathrm{C}$ was limited by the oven used in this experiment. The maximum surface relief amplitudes were observed in samples baked at $210^{\circ} \mathrm{C}$. Control measurement of the weight of the photopolymer layers revealed that the increase in the surface amplitude is accompanied by decrease in the sample mass. Most probably the mechanism of surface relief formation after thermal treatment is related to spatially modulated evaporation of TEA whose boiling temperature is $208^{\circ} \mathrm{C}$.

a)
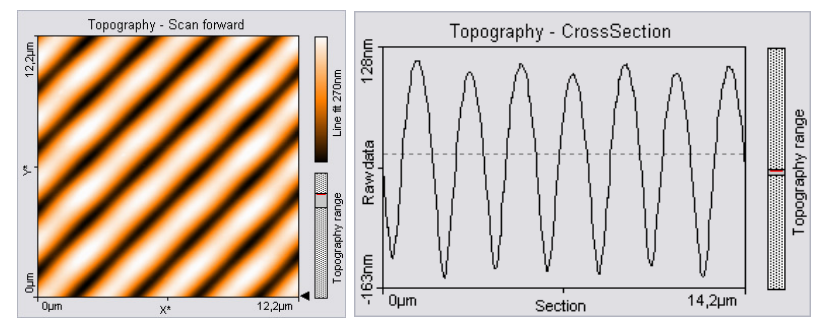

b)
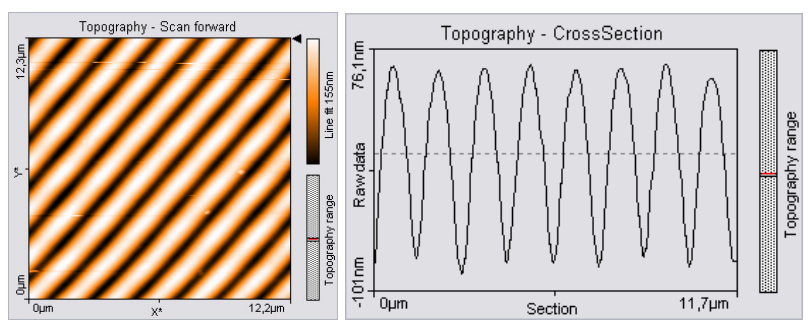

c)
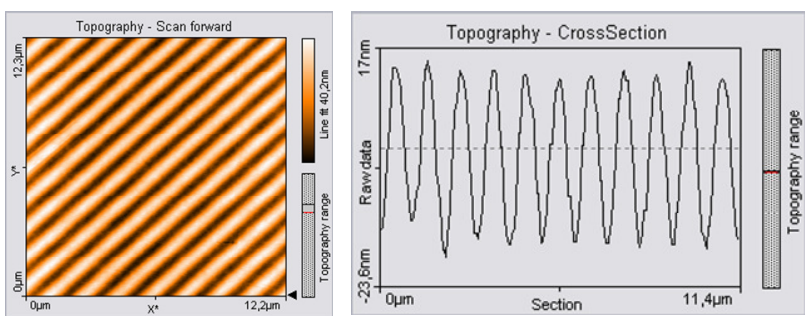

FIGURE 3 Holographically inscribed surface relief gratings of spatial frequency a) 500 1/mm; SRA = $260 \mathrm{~nm}$; b) 7001/mm; $\mathrm{SRA}=150 \mathrm{~nm}$; ) $10001 / \mathrm{mm} ; \mathrm{SRA}=35 \mathrm{~nm}$.

\section{Spatial Light Modulator experiment}

The aim of this experiment was to study the properties of the surface relief modulation inscribed by imaging the pattern on a SLM onto the photopolymer layer. An asymmetric pattern (Figure 4a) of white rectangles on a black background was chosen in order to allow correlation of the location of the surface relief peaks and the locations of the illuminated areas. As one can see in Fig $4 \mathrm{~b}$ the surface relief peaks correspond to the illuminated areas. This is in agreement with our previous studies of the location of the surface relief peaks in holographically recorded structures [5].

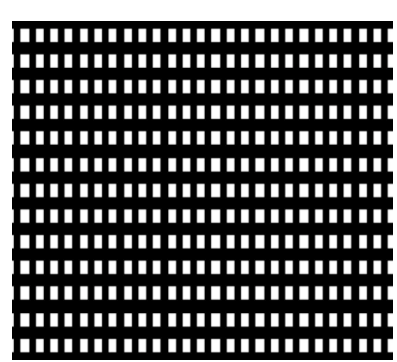

a)

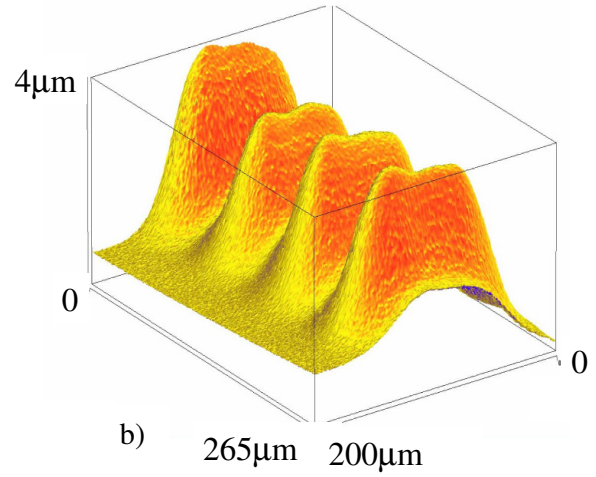

b) $265 \mu \mathrm{m} \quad 200 \mu \mathrm{m}$

FIGURE 4. Pattern on the SLM a) and surface relief profile inscribed in the photopolymer layer 
Comparison of the SRA achieved by illumination trough a SLM and the amplitude of holographically inscribed patterns of the same spatial frequency of $16 \mathrm{l} / \mathrm{mm}$ shows that the first process is more effective. The SRA at $161 / \mathrm{mm}$ achieved using holographic recording was less than $1 \mu \mathrm{m}$ while by using a SLM SRA of $3.5 \mu \mathrm{m}$ was achieved.

\section{CONCLUSIONS}

In summary, a post recording thermal treatment is required for achievement of sub-micrometer surface relief profiles. The development of the surface relief profile is accompanied by a mass loss. The highest SRA was observed after baking above $200^{\circ} \mathrm{C}$. This suggests that the mechanism of high temperature surface relief formation could be related to a spatially modulated evaporation of TEA. A successful fabrication of surface relief profiles with amplitude of $15 \mathrm{~nm}$ and spatial frequency of 1550 lines $/ \mathrm{mm}$ by holographic patterning was demonstrated. The initial results from surface patterning by utilising a SLM demonstrate that when compared to holographic recording this technique at the same geometry and recording conditions leads to a higher surface relief amplitudes. Further improvement of the optical set-up is required to test the high spatial frequency response of the material using this technique.

\section{ACKNOWLEDGMENTS}

The authors would like to acknowledge the COST MO604 action for funding the visit of Dr. Nazarova to the Centre for Industrial and Engineering Optics in Dublin and Dr. Suzanne Martin for the useful discussions.

\section{REFERENCES}

1. S. Martin, P. Leclere, V. Toal, and Y. Lion, "Characterization of an acrylamide-based dry photopolymer holographic recording material", Optical Engineering, 3312 3942-3946, (1994).

2. S. Martin, C.A. Feely and V. Toal, "Holographic recording characteristics of an acrylamide-based photopolymer", Appl. Optics 36, 5757-5768, (1997).

3. I. Naydenova, S. Martin, R. Jallapuram, R. Howard, V. Toal, Investigations of the diffusion processes in self-processing acrylamide-based photopolymer system, Applied Optics, 43 (14), 2900, 2004.

4. R. Jallapuram, I. Naydenova, S. Martin, R. Howard, V. Toal, Sven Frohmann, Susanna Orlic, Hans J Eichler, Acrylamide based photopolymer for micro-holographic data storage, Optical Materials, 28 (12) , 329-1333, 2006.

5. I. Naydenova, E. Mihaylova, S. Martin, V. Toal, "Holographic patterning of acrylamide-based photopolymer surface", Optics Express, 13, 4878-4889, (2005).

6. I. Naydenova, K. Pavani, E. Mihaylova, K. Loudmer, S. Martin, V. Toal "Holographic recording of patterns in thin film acrylamide-based photopolymer "," SPIE proceedings of OPTO-IRELAND, V. 5827, 163-172, 2005.

7. K. Pavani, I. Naydenova, S. Martin and V. Toal, Photoinduced surface relief studies in an acrylamide-based photopolymer, J. Opt. A: Pure Appl. Opt. 9 (2007) 43-48.

8. J. Jenney, "Holographic recording with photopolymers", JOSA 60, 1155-1161, (1970).

9. Y. Boiko, V. Slovjev, S. Calixto and D. Lougnot, "Dry photopolymer films for computer-generated infrared radiation focusing elements," Appl. Opt. 33, 787-793, (1994).

9. C. Croutxe-Barghorn and D. Lougnot, "Use of self-processing dry photopolymers for the generation of relief optical elements: a photochemical study," Pure Appl. Opt. 5, 811-825, (1996).

11. T. Smirnova and O. Sakhno, "A mechanism of the relief-phase structure formation in self-developing photopolymers," Optics and Spectroscopy 3, 126-131, (2001). 